\title{
Deporte e inmigración. \\ Cobertura mediática y repercusión social de la selección nacional de fútbol de Francia
}

\author{
Noemi GARCÍA-ARJONA \\ Universidad Politécnica de Madrid \\ noemi.garcia.arjona@upm.es
}

Recibido: 31 de mayo de 2012.

Aceptado: 15 de julio de 2012.

\begin{abstract}
Resumen
El impacto social del fútbol en nuestros días es innegable, y la representación de un país a través de su selección se convierte en cuestión de Estado; en torno al equipo nacional se forma un discurso que refuerza las virtudes integradoras del deporte pero también cuestiona las dinámicas de identidad, patriotismo y prejuicio. Se ha tomado como ejemplo a la selección francesa de fútbol, caracterizada por una diversidad social y cultural fruto de su historia reciente. Se analizarán cuatro hechos que han configurado su evolución en la repercusión social de la opinión pública francesa, a saber: la victoria en el Mundial de 1998, el partido Francia-Argelia de 2001, la huelga de jugadores en el Mundial de 2010, y el caso de las cuotas raciales en 2011. A través de la prensa generalista (Le Monde) como deportiva ( $L$ 'Équipe), se analizará este discurso en torno a la selección de fútbol, haciendo hincapié en el papel protagonista de los medios dentro de la propia noticia.
\end{abstract}

Palabras clave: Fútbol; inmigración; Francia; prensa; identidad.

\section{Sport and immigration. Media coverage and social impact of the France national soccer team}

\begin{abstract}
Today, the social impact of football is undeniable, and the representation of a country through its team becomes a State matter; a discourse around the national team is raised, whether to reinforce the integrative virtues of sport or to query the dynamics of identity, patriotism and prejudice. The French national football team has been taken as example, characterized by a social and cultural diversity as a result of its recent history. Four events that have shaped its evolution in the social impact of French public opinion will be analyzed: the 1998 World Cup victory, the match France-Algeria in 2001, the players' strike in the 2010 World Cup, and the case of racial quotas in 2011. Through the mainstream (Le Monde) and sports (L'Équipe) press, it will be analyzed the discourse around the football team, emphasizing the role of media within the news itself.
\end{abstract}

Key words: Football; immigration; France; press; identity.

\section{Referencia normalizada}

García-Arjona, N. (2012). Deporte e inmigración. Cobertura mediática y repercusión social de la selección nacional de fútbol en Francia. Historia y Comunicación Social, Vol. 17, páginas 85-102.

Sumario: 1. Introducción; 2. Un corpus sobre deporte: Le Monde y L'Équipe; 3. Los Bleus, ¿reflejo de una Francia multicultural?; 4. Conclusiones; 5. Bibliografía. 


\section{Introducción}

El fútbol es un fenómeno global en sí mismo. Por su continua exposición mediática y peso económico, este deporte se ha convertido en un elemento más de análisis de las sociedades actuales. Dicho peso social permite a su vez la consolidación de un imaginario colectivo, de identidad grupal y de afirmación. Así,

el deporte es culturalmente y políticamente importante desde el punto de vista de la representación de personas y de colectivos. Los equipos representan simbólicamente a las sociedades, locales y nacionales (...) pero estas identificaciones pueden entrar en tensión, particularmente en deportes como el fútbol o el deporte olímpico donde el público espera identificarse con el equipo nacional. El deporte propone el discurso sobre la nación, sobre lo que significa ser francés (o alemán, o británico) (Ndiaye, 2010:261).

En el caso de Francia, la victoria en la Copa del Mundo de 1998 y la Copa de Europa de 2000 generó un sentimiento colectivo que podría hacer olvidar diferencias sociales y culturales, en un "mestizaje a través del fútbol", gracias a la meritocracia que permite el sistema deportivo (Queval, 2004); políticos, opinión pública y los propios protagonistas impulsaron la idea de que, si un multiculturalismo en lo deportivo había sido posible, también lo podría ser en el ámbito social.

Pero la selección black-blanc-beur ${ }^{1}$ de 1998 y 2000 no fue la primera caracterizada por la diversidad de razas, orígenes y religiones. De hecho, la historia del fútbol francés puede escribirse a través de la presencia de jugadores de origen extranjero. La movilidad social que permite el fútbol, su profesionalización y la relación histórica post-colonial de Francia con otros países (sobre todo de África) permiten comprender la evolución de la selección francesa en este aspecto.

Desde el periodo de entre guerras, la presencia de jugadores de origen extranjero en el equipo de los Bleus ${ }^{2}$ es notable. La historia migratoria de Francia está marcada por la llegada de población europea del sur (sobre todo italianos, portugueses, y españoles) durante el periodo de crecimiento económico de los Treinta Gloriosos (1945-1973), de los que también se benefició el fútbol francés, profesionalizado desde 1932. Más tardíamente se darían movimientos migratorios producto de la descolonización africana, con inmigración procedente de países subsaharianos y de Maghreb, así como de territorios y departamentos de ultra-mar (Boubeker y Galloro, 2011). Poco a poco se fueron creando los primeros clubes, y los emergentes talentos se convirtieron en referencia para las distintas comunidades de las ciudades francesas, tanto jugadores de la primera generación como los hijos y nietos de inmigrantes; así, el fútbol empezó a configurarse como un posible vector de ascenso social. La trayectoria de los jugadores variará enormemente, desde los que se nacionalizaron hasta los que, nacidos en Francia, decidieron representar al país de origen de sus padres. Esto supondrá un cuestionamiento de las identidades locales y nacionales, sociales y culturales. Un ejemplo de este "extrañamiento cultural" (Checa Olmos, Arjona y Checa, 2007), quedará reflejado en el polémico amistoso en 2001 que enfrentó a Francia contra Argelia, el cual empezó con pitidos a la Marsellesa y terminó con la invasión del campo por parte de los espectadores. 
Cuando los Bleus ganaron el Mundial, la sociedad francesa vio en el éxito deportivo una posible solución a la dificultad de cohabitación de culturas. Considerada tradicionalmente como nación de inmigración, la política de acogida de Francia está basada en la laicidad e igualdad de los ciudadanos, quedando los valores republicanos por encima de cualquier diferencia ("igualdad, libertad, fraternidad"); existe una separación entre el dominio público y el privado, donde la laicidad es uno de los principios básicos de la idiosincrasia republicana francesa. Sin embargo, este modelo no sería suficiente para lograr la plena adaptación de la población inmigrante en la ciudadanía francesa. Criticada por ser demasiado asimilacionista ${ }^{3}$, sus detractores denuncian precisamente que el no reconocimiento del origen en la esfera pública llevaría a una invisibilidad del bagaje cultural de una parte importante de la población francesa (Simon y Zappi, 2003).

En este sentido, parece necesario que hagamos previamente una distinción sobre la problemática de categorización de "inmigrante" o "extranjero", particular en el caso francés. Las nociones de raza, cultura, etnia o religión están presentes en mayor o menor medida, pero resultan insuficientes; parece ser entonces que la categoría de origen o procedencia es la más coherente para abarcar todos estos elementos (Lagrange, 2010:21). Podemos hablar entonces de inmigrantes (nacidos de padres franceses), de "segunda generación" (nacidos en Francia, de descendencia inmigrante) y los originarios de Dom-Tom ${ }^{4}$, nacidos en territorios de ultramar que pertenecen administrativamente a Francia, y se consideran regiones como en el resto del territorio hexagonal. De forma paralela, la etnificación de la población francesa va a establecerse principalmente en zonas urbanas llamadas "sensibles" o banlieues 5 , alejadas del centro de la ciudad. La distancia va a ser tanto urbana, social como cultural. Pero esta última dimensión será la más ignorada en los estudios que tratan de explicar la falta de cohesión social, hecho que se ha considerado una "negación de las culturas". Los motines violentos en las banlieues de varias ciudades francesas en 2005 fomentaron el estigma urbano y la "guetización" de los jóvenes hijos de inmigrantes, y pusieron en cuestión la política social, educativa y de integración en Francia. Una consecuencia de esta situación fue el debate de "identidad nacional" lanzado en las presidenciales de 2007, que se criticó por su clara politización reforzando prejuicios negativos hacia la población inmigrante, y "fabricando una división artificial entre «ellos»y «nosotros»" (Noiriel, 2007: 7).

En este contexto, los Bleus protagonizarán en el Mundial de Sudáfrica de 2010 uno de los episodios más sombríos de su historia: expulsión de un jugador de la concentración por insultar al seleccionador, huelga de jugadores y eliminación prematura de la competición. Meses más tarde, saltaría la noticia que pondría en tela de juicio a la propia Federación Francesa de Fútbol (FFF): un supuesto sistema de cuotas raciales se estaría imponiendo en los centros de formación de jóvenes jugadores. La opinión pública, que no podía olvidar el éxito del 98, va a interpretar estos dos últimos hechos como el símbolo de un fracaso no solo deportivo, sino también social e identitario.

El objetivo de este artículo busca analizar y comprender la evolución y el impacto de la selección francesa de fútbol en la sociedad a través de los éxitos y fracasos deportivos de los últimos quince años. 


\section{Un Corpus sobre deporte: Le Monde y L'Equipe}

Para la construcción del corpus de referencia, el análisis se ha centrado en la búsqueda del discurso del deporte en tanto que actividad cultural, el papel de la selección francesa y lo que representa para su sociedad. Para este análisis, nos valemos de la prensa (general y especializada) como principal fuente de información, por su impacto innegable en la opinión pública francesa hacia su selección de fútbol. Su papel decisivo como fuente histórica, social y política y su implicación en la definición y configuración de los hechos sociales es obvia; la noticia no es en sí extrínseca al acto o suceso que narra, ni se realiza de manera anónima o "neutra": hay una intención, una clara selección (u omisión) del qué y del cómo se va a tratar la noticia.

Cuatro son los casos de estudio seleccionados a lo largo del periodo 1998-2011: la victoria de la selección en el Mundial del 98, el partido amistoso de 2001 entre Francia y Argelia, el Mundial de Sudáfrica en 2010 y el caso de las supuestas "cuotas" raciales por parte la FFF, en 2011. La profunda transformación de la imagen pública de los Bleus, pasando de héroes a villanos en apenas 13 años, sólo podría ser comprensible con una mirada retrospectiva de los principales sucesos a través de un análisis comparativo.

Para ello se han seleccionado dos periódicos diarios como fuente de información principal: uno generalista, Le Monde, y el deportivo L'Équipe. Ambos ocupan, respectivamente, el segundo y tercer puesto en el ránking nacional de periódicos de pago con mayor difusión, según datos recientes de la Asociación de Medios en Francia 6 .

Le Monde cuenta con una tirada de 292.062 ejemplares diarios. El diario fue fundado en diciembre de 1944, después de que el general De Gaulle restableciera la publicación de periódicos independientes en la Francia libre (Poulet, 2003: 41). Le Monde se caracterizó desde sus comienzos por un claro carácter internacional, de izquierdas y liberal, con una línea editorial independiente "que le asegura una legitimidad, desde hace tiempo, de carácter excepcional en el panorama mediático y político francés" (Eveno, 2001: 26).

El caso del diario deportivo L'Équipe, con la publicación de su primer número en febrero de 1946, posee una cuota algo inferior a Le Monde (285.386 ejemplares), ostentando sin embargo un claro monopolio en cuanto a información deportiva en Francia se refiere. Heredero de L'Auto, la referencia deportiva anterior a la II Guerra Mundial, se consagró en sus inicios principalmente al ciclismo, pero con el tiempo va a diversificar su atención a la cobertura de otros deportes, principalmente el fútbol. El monopolio indiscutible de este rotativo ha sido también blanco de críticas por la aparente contradicción de sus objetivos, que basculan entre una línea de exaltación del campeón a través de primicias en polémicas portadas, o el tratamiento exigente y riguroso de la actualidad deportiva (García, 2008).

La comparación de prensa especializada con la general va a permitir recuperar desde un punto de vista más plural el discurso predominante hacia el deporte, a través de los periodistas y de influyentes cronistas. El fútbol se constituye como 
verdadero "fenómeno social" para que el público lector lo tome como suyo: ya sea en la victoria como en el fracaso, el diario va a emitir un juicio sobre la selección y su importancia social. Es importante también retener el papel del periodista dentro del proceso de formulación de la noticias que giran en torno a los Bleus, el cual, por voluntad o a su pesar, puede convertirse en "juez" del caso que aborda, dictaminando una u otra resolución a través de su discurso personal y de la línea editorial del periódico. Además, la inmediatez de las fuentes de información como la prensa escrita ofrece un denso material con el que comparar entre sí o con otros formatos, utilizados también en este análisis de manera complementaria (entrevistas filmadas, periódicos digitales, páginas web, reportajes y documentales temáticos).

El análisis de los eventos se ha realizado a través de las ediciones electrónicas de los dos periódicos a través de la hemeroteca digital, así como a través de artículos científicos que han abordado previamente esta problemática; esto ha permitido localizar y filtrar las fechas clave y los principales artículos de los eventos a analizar. Se realizó una búsqueda sistemática en torno a las fechas de los sucesos, entre dos y tres meses antes y después. En el caso del amistoso Francia-Argelia, la búsqueda se prolongó desde octubre de 2001 (fecha del evento) hasta junio de 2002 (periodo electoral), por la implicación política de los hechos que hizo emerger más artículos referidos al suceso. Los criterios de selección de la noticia estaban dirigidos a la referencia del periodista de manera directa o indirecta al origen o procedencia del jugador/es de la selección.

En esta primera fase de análisis cuantitativo se recuperaron un total de 160 artículos relevantes en esta temática; de éstos, 38 sobre el Mundial del 98, 40 sobre el partido de Francia-Argelia, 43 del Mundial de 2010, y 39 del caso de las cuotas en 2011. En estos dos últimos casos se ha complementado la búsqueda con la versión digital del periódico y de otros portales de documentación e información, como Mediapart, que tendrá un papel decisivo en el caso de las cuotas de 2011. En segundo lugar, se ha procedido al análisis de contenido de los artículos seleccionados, localizados en los archivos de ambos periódicos (en formato digitalizado, papel o microfilm, éste último para el caso del Mundial 98), en torno a los cuatro casos seleccionados.

\section{Los Bleus, ¿Reflejo de la Francia multicultural?}

A continuación se presenta el análisis de los eventos que han marcado la historia migratoria y deportiva de la selección francesa de fútbol. En el siguiente cuadro (cuadro 1) se recogen de manera sucinta la cronología de los acontecimientos clave; en los apartados siguientes se analizarán dichos sucesos a través de los periódicos seleccionados. 
3.1. La selección "tricolor y multicolor", campeona del mundo

Cuadro 1. Cronología de las noticias, fecha y titulares (1998-2010).

\begin{tabular}{|c|c|c|}
\hline Noticia & Fecha & Titulares \\
\hline $\begin{array}{l}\text { Francia se proclama campeona del } \\
\text { Mundo de fútbol }\end{array}$ & 12 de julio de 1998 & $\begin{array}{l}\text { "Heroicos" (L'Équipe, } 9 \text { de julio) } \\
\text { "Para la eternidad" (L'Équipe, } 13 \text { de julio) } \\
\text { "El país se reconoce a través de este equipo } \\
\text { multiétnico"(Le Monde, } 18 \text { julio) }\end{array}$ \\
\hline $\begin{array}{l}\text { El partido amistoso Francia-Algeria } \\
\text { en el Stade de France (París) es } \\
\text { interrumpido en el minuto } 76 \text { de } \\
\text { juego }\end{array}$ & 6 de octubre de 2001 & $\begin{array}{l}\text { "Francia-Argelia: un reencuentro con múltiples } \\
\text { retos" (Le Monde, } 6 \text { de octubre) } \\
\text { "Una gran decepción" "Historia de un fracaso" } \\
\text { (L'Équipe, } 7 \text { de julio) } \\
\text { "El partido Francia-Argelia de la reconciliación } \\
\text { queda por jugar" (Le Monde, } 9 \text { de octubre) }\end{array}$ \\
\hline $\begin{array}{l}\text { La selección se niega a entrenar } \\
\text { como protesta por la expulsión de } \\
\text { Nicolas Anelka; Francia es } \\
\text { eliminada de la Copa del Mundo en } \\
\text { Sudáfrica en primera ronda contra } \\
\text { la selección anfitriona }\end{array}$ & 20-22 de junio de 2010 & $\begin{array}{l}\text { "El crepúsculo de los Bleus" (Le Monde, } 21 \text { de } \\
\text { junio) } \\
\text { "Patas arriba: huelga, dimisión, psicodrama... sólo } \\
\text { queda una cuestión: ¿los Bleus pueden caer más } \\
\text { bajo?" (Le Monde, } 22 \text { de junio) } \\
\text { "La última humillación" (L'Équipe, } 21 \text { de junio) }\end{array}$ \\
\hline $\begin{array}{l}\text { Reunión de la Dirección Técnica } \\
\text { Nacional de la Federación Francesa } \\
\text { de Fútbol, sobre la formación de } \\
\text { jóvenes jugadores }\end{array}$ & $\begin{array}{l}8 \text { de noviembre de } 2010 . \\
\text { La noticia aparece el } 28 \\
\text { de abril de } 2011 \text { en } \\
\text { Mediapart.fr }\end{array}$ & $\begin{array}{l}\text { "Fútbol francés: los directivos quieren menos } \\
\text { negros y árabes" (Mediapart.fr, } 28 \text { de abril) } \\
\text { "La FFF [Federación Francesa de Fútbol] en un } \\
\text { nuevo temporal" (L'Équipe, } 30 \text { de abril) } \\
\text { "La Féderación a punto de explotar (L'Équipe, } 2 \\
\text { de mayo) } \\
\text { "La Federación Francesa de los escándalos" (Le } \\
\text { Monde, } 11 \text { de mayo) } \\
\text { "Las cuotas en el fútbol, reflejo de la Francia post- } \\
\text { colonial"(Le Monde, } 18 \text { de mayo) }\end{array}$ \\
\hline
\end{tabular}

Fuente: Le Monde y L'Équipe

Francia acogió desde el 10 de junio al 12 de julio de 1998 la Copa del Mundo de fútbol. "Bienvenidos al mundo", era el cartel que recorría las calles de París. La organización del evento no fue del todo fácil: hubo que construir un nuevo estadio (Stade de France, al norte de París), y se evidenció una dificultad para convencer a los actores implicados (gestores deportivos, clubes, empresas de publicidad, políticos, y la opinión pública en general). La presión para el equipo de los Bleus era grande: Francia nunca había ganado un Mundial, ni siquiera había pasado a una final. Hubo también dudas en el estilo de juego: el seleccionador Aimé Jacquet fue blanco de duras críticas, en especial por parte de L'Équipe, lo que supuso una dura disputa entre Jacquet y el rotativo, como después el seleccionador aseguraba en una entre- 
vista para Le Monde .

A pesar de estas dudas iniciales, y según la selección se iba clasificando, el discurso de ambos periódicos elogiaba el juego y la cohesión de un equipo con jugadores de distintos orígenes culturales y sociales. Efectivamente, es a medida que los Bleus van clasificándose cuando el discurso de una selección multicultural se ensalzaba como rasgo positivo, e idealmente representativo, de la identidad francesa. Por ejemplo, después de la victoria sobre Croacia (2-1) que les llevaría por primera vez a una, en este caso contra contra Brasil, L'Équipe recoge en portada8:

Ella [Francia] ha descubierto, en el transcurso de estas últimas semanas, que el fútbol puede ser una ocasión única de reconocerse entre todos, sin importar dónde se haya nacido, el color de la piel, o cómo se piense (...). Esta Copa del mundo también ha permitido sobre todo recordar a aquellos que lo olvidan fácilmente, que este país es una maravilla y que se pueden hacer grandes cosas.

Tanto Le Monde como L'Équipe recogen en diferentes artículos el hecho de que los jugadores tengan orígenes extranjeros. El hecho era evidente: de los 22 jugadores convocados, algunos eran de origen inmigrante (Desailly,Vieira), de segunda o tercera generación (Charbonnier, Trezeguet, Djorkaeff, Henry, Pires, Zidane) o procedentes de Dom-Tom (Lama, Thuram, Karembeu). Este hecho es subrayado por el periodista, como ejemplo de "modélica integración", y reflejo de cómo el fútbol permite esta promoción social; de este modo, son los elementos social y cultural los que destacan en las crónicas. En el caso de Youri Djorkaeff, perteneciente a la tercera generación de inmigrantes armenios en Francia, se destaca que procede de una banlieue de Lyon llamada Décines, la cual contaba con una comunidad armenia del $15 \%$ en ese momento. Youri es visto como un héroe local, como un símbolo de "éxito" y "orgullo" para el pueblo armenio?.

Pero quien sin duda va a acaparar más atención es la figura de Zinedine Zidane. Sin ser el capitán del equipo, siéndolo Didier Deschamps, "Zizou” va a asumir un papel de líder dentro y fuera del campo, identificándose con orgullo con sus dos orígenes: el francés y el argelino bereber (cabilio o kabyl en francés); así, el jugador afirmaba antes del comienzo del Mundial: "jugaré por los míos y por la Francia entera (...); yo no olvido que soy de Marsella. Hoy, soy yo quien va a hacer soñar a la gente" 10 . El sentir de los habitantes de La Castellane, barrio popular de la banlieue de Marsella, donde Zidane creció y empezó a jugar al fútbol, también cristalizaba la creación de un referente, idolatrado entre sus vecinos, que habría podido triunfar en la vida gracias al fútbol: "para nosotros, Zidane es un Dios"11.

El discurso de un equipo francés multicultural triunfante, reflejo de su sociedad, también es defendido por los propios protagonistas, en este caso por parte del seleccionador y del capitán del equipo; Aimé Jacquet aseguraba en una entrevista a Le Monde que "Francia se reconoce a través de este equipo multiétnico, ¿qué hay más bello que eso?"12, y más tarde: "es un buen impulso para la unidad nacional y para dar confianza a un país que tiene tendencia a dudar de sus capacidades. Se dice que los Bleus han contribuido a la batalla Anti-Le Pen: por eso estoy muy contento y muy 
orgulloso"13, como réplica a las polémicas declaraciones durante la Eurocopa del 96, por parte del presidente del partido de extrema derecha Frente Nacional (FN), en las que criticaba que algunos de los jugadores no hubieran cantado La Marsellesa. Didier Deschamps diría tras ganar el Mundial: "El fútbol es un vector que permite borrar las diferencias raciales, sociales o políticas"14.

La opinión pública tampoco quedaría al margen de este sentimiento de una identidad nacional plural, de lo positivo que representaba la selección black-blanc-beur. Le Monde dedicó un artículo a la probabilidad de esta transmisión del éxito deportivo a la arena pública, un día después de proclamarse campeones: "Si la mezcla se consigue en el fútbol, puede hacerse también en la calle"15. En esta noticia se recogen diferentes testimonios de seguidores que, a pesar de no tener una opinión unánime con respecto al "efecto Mundial" en la sociedad francesa, sí admiten en su mayoría el enorme impacto de un equipo que recogía un sentimiento colectivo: se puede vivir juntos. Un ejemplo de esto son las declaraciones de unos jóvenes aficionados procedentes de Saint-Denis, un suburbio del norte de París con un elevado número de población inmigrante, el día de la celebración en la capital francesa: "estamos aquí para festejar, no para armar follón [sic]. El equipo de Francia es nuestro equipo. Henry, Trezeguet, son nuestros primos, ellos vienen de la banlieue como nosotros".

El equipo fue recibido en multitud en su paseo por los Campos Elíseos, fueron tratados como héroes nacionales e investidos Caballeros de la Legión de Honor. Su victoria, además, coincidió con la Fiesta Nacional del 14 de julio, por lo que resultó fácil vincular la identificación deportiva con un sentimiento patriótico. El gesto que definitivamente cristalizó esta intención se dio en el discurso del Presidente de la República, Jacques Chirac, que se refirió así a la proeza futbolística: "este equipo a la vez tricolor y multicolor da una bella imagen de la Francia que tiene de humanista y fuerte" (...). En el fondo, esta victoria muestra la solidaridad, la cohesión (...); yo espero que el día de mañana después de estos días de fiesta, se conserve este sentimiento nacional (...); la Francia tiene históricamente un origen plural"16. El efecto Copa del Mundo no tardaría en llegar: el Stade de France se convertiría en un "lugar de culto y peregrinaje" 17 , y a final de año se contabilizó un aumento muy significativo de nuevas licencias federativas ${ }^{18}$. El célebre documental de Canal +, "Les yeux dans les Bleus", que relata el día a día de los jugadores durante la copa del Mundo, va a contribuir a la mitificación de esta selección (Stéphane Meunier y Canal +, 1998).

Sobre este primer evento, podemos extraer unas primeras reflexiones: en primer lugar, es interesante retener el hecho de que los dos periódicos analizados subrayan el origen cultural y social diverso de los jugadores desde una óptica positiva. Pero al mismo tiempo, es a través de este tratamiento como se ayudaría a fomentar y consolidar un discurso, un ideal anhelado casi dogmático, en el que el deporte sería una vía de integración social y cultural. 


\subsection{El amistoso Francia-Algeria}

El segundo acontecimiento objeto de análisis va a suceder apenas tres años después de la apoteosis mundialística, y un año de la victoria en la Eurocopa 2000. Con el objetivo de celebrar la reconciliación de los países de Francia y Argelia después de la guerra de independencia (1954-1962), se decidió organizar un encuentro amistoso entre las dos selecciones, en el Stade de France, el 6 de octubre de 2001.

Tanto prensa como opinión pública se volcaron en lo que se calificó de encuentro "histórico". Se valoró como un evento que trascendía lo meramente deportivo, en clave de gesto diplomático de cordialidad y mutuo respeto. Dicha expectación se reflejó en la cobertura mediática del evento, antes y después. Es de subrayar que periódicos generales como Le Monde dedicaran numerosos artículos fuera de la sección deportiva, como en los apartados de Debate o Política, incluso hasta las elecciones presidenciales de 2002, por los hechos acontecidos y sus consecuencias que veremos a continuación.

En los antecedentes al partido, el enfrentamiento Francia-Argelia era considerado efectivamente de poca relevancia deportiva, pero en sí representaba importantes vicisitudes políticas e históricas: la reconciliación entre los dos países, la integración de jóvenes inmigrantes o de padres argelinos en Francia, la identidad nacional, y la gestión de la diversidad cultural. El encuentro, fue, por tanto, instrumentalizado por ambos gobiernos y sirvió de excusa a la prensa para abordar el pasado histórico y deportivo de las dos selecciones ${ }^{19}$, aprovechando en ambos casos, el impulso mediático de la victoria del 98.

Sin embargo, los prolegómenos del partido van a sufrir un giro radical: el 11 de septiembre se producen los atentados terroristas en Nueva York. Se refuerza la seguridad en el Estadio, y a partir de ese momento, el encuentro es considerado por la FIFA "de alto riesgo", como reflejara L'Équipe un día antes: "amistad bajo vigilancia" 20 . Fue tal la psicosis por un posible acto terrorista, con fuertes medias de seguridad sobre el estadio, que se llegó a hablar de la suspensión del partido. Para más inri, la cobertura mediática fue enorme para tratarse de un partido amistoso, y el Stade de France colgó el cartel de "completo". En tales circunstancias, las autoridades políticas, como la ministra de Juventud y Deporte, Marie-George Buffet, no consideraron la vía de la suspensión, que ya en sí hubiera significado un fracaso ${ }^{21}$; pero yendo incluso más allá, la no celebración del partido hubiera supuesto la claudicación ante la paranoia terrorista e islamofóbica en la que se encontraba Francia y el resto de países occidentales.

En cuanto a la opinión pública, y en concreto, los franceses de origen argelino (segunda o tercera generación), el partido supuso un "despertar identitario", que tendría consecuencias más o menos positivas (Gastaut, 2008: 51). En efecto, la problemática del biculturalismo era un delicado asunto que reflejaba cómo dos países todavía guardaban una relación post-colonial sobre la que todavía pesaba un doloroso pasado histórico. Es de nuevo Zidane por su origen argelino quien acapara una atención especial, significando para él un extraño sentimiento de doble perte- 
nencia, de "emoción contenida" 22 . El caso de Zidane, ya encumbrado como ídolo, es considerado como ejemplo de posible biculturalismo; los jóvenes argelinos que irán a animar el partido se identifican con las raíces de su país natal (Francia) y con las de sus padres o abuelos (Argelia). El enfrentamiento, por todas estas razones, se va a percibir como una prueba en la que se comprobaría hasta qué punto la reconciliación entre los dos países y la integración de los jóvenes de origen argelino era realmente cierta.

Y llegó el día del partido. Pero no empezó con buen pie: La Marsellesa es abucheada y pitada por una amplia parte de las gradas. El partido se desarrolló sin mayor problema, siendo el equipo de los Bleus quien dominara el marcador por 4-1. Pero en el minuto 76 de juego comenzó la invasión del campo por los aficionados, al principio de manera aislada, con algunos hinchas porteando la bandera argelina, $\mathrm{y}$ después cientos de aficionados consiguen rebasar las medidas de seguridad, bajo el enorme griterío de los demás espectadores en la grada. La situación se hizo insostenible a pesar de que los agentes de seguridad intentaron retener la marea humana sobre el césped, pero definitivamente el árbitro suspendió el partido: la imagen de los jugadores saliendo en carrera hacia los vestuarios, y la invasión completa del campo dio la vuelta al mundo. Sería un partido, el de la reconciliación, "que quedaría por jugar"23.

En medio de la confusión total durante la invasión del campo, las cámaras de televisión captaron uno de los momentos más comentados: el del defensa Lilian Thuram ${ }^{24}$ que regaña enérgicamente a uno de los jóvenes espectadores: “¿No te das cuentas de lo que haces? ¿No te das cuenta de que refuerzas todos los prejuicios que hay sobre ti? Luego vas a llorar y vas a decir que no entiendes nada" (Gastaut, 2008: 62).

Una investigación por parte de la FIFA y de las autoridades francesas se puso en marcha después de los incidentes, pues se barajó en todo momento la tesis de una operación premeditada, hecho que finalmente se confirmó no ser cierto. Las críticas, por un lado, se centraron en la condenación unánime de los hechos, tanto por parte de la prensa francesa como la argelina. Los medios tildaron los incidentes de "fracaso" y "verdadera decepción", siendo la editorial de ese día del periódico L'Équipe la más radical: "insultante", refiriéndose al conjunto de la comunidad argelina, que habría sido "humillada" 25. La clase política, con el Primer Ministro francés Lionel Jospin a la cabeza de las declaraciones, se centró en relativizar los altercados, precisamente para evitar juicios precipitados; por otro lado, la organización y seguridad del partido fueron objetivo de duras críticas.

En definitiva, podemos observar dos tipos de consecuencias de este evento: en el plano deportivo, los incidentes del Francia-Argelia provocaron un sentimiento de menor identificación con la selección francesa de fútbol, tanto de público como de jugadores; Stéphane Beaud, en un acertado análisis sobre la evolución de los Bleus y sus orígenes sociales y culturales desde 1998 hasta 2010, sostiene la hipótesis de que, directa o indirectamente, la presencia de beurs en la selección habría sido menor a partir de esa fecha, también motivado por una "fuga de jugadores" a las selecciones de origen, incluso habiendo nacido y crecido en Francia. Este caso no se da solo en jugadores de origen magrebí, sino en el resto de África; un ejemplo de esta casuís- 
tica sería el jugador Didier Drogba, héroe reciente de la victoria en la Champions League 2012 con el equipo inglés Chelsea: nacido en Costa de Marfil, y criado en Brest (Bretaña francesa), decidió jugar con la camiseta marfileña, asumiendo además la capitanía de su selección, y por tanto, consiguiendo el estatus de "internacional", muy valorado con vistas al mercado de fichajes de los clubes.

La segunda consecuencia, política y social, se revelaba, en efecto, mucho más profunda: aunque no todos los que invadieron el campo compartían este sentimiento, sí era evidente que una generación de jóvenes no se sentían identificados con su país de nacimiento, Francia. Cabe resaltar la reacción de la ministra Buffet, agredida sin gravedad en el palco por botellas lanzadas por algunos hinchas (posteriormente juzgados con prisión), quien asumió parte de la responsabilidad de los hechos al declarar: "estimo que el desbordamiento se ha dado por una focalización sobre el riesgo de atentados"26; esto vino a corroborar el malestar y desencanto de jóvenes en claro conflicto identitario, a lo que se unió lo que no se pudo evitar: una deformación de los hechos que llevó a un creciente prejuicio en la opinión pública hacia lo musulmán, lo árabe y lo extranjero. El conflicto de la alteridad en el ámbito social y urbano también va a estar presente de manera recíproca: el mundo de "nosotros" (el barrio popular, la banlieue) y el mundo de "ellos" (los ricos, los "burgueses"). Hasta las Presidenciales de 2002, el altercado fue utilizado como posible hipótesis explicativa al creciente discurso manipulado sobre la (in)seguridad por delante de la integración, haciendo que se cristalizaran prejuicios y confusión sobre las categorías religiosas, culturales y sociales, de manera intencionadamente electoralista; en este sentido, es destacable la columna en Le Monde que firmaron 85 personalidades del mundo educativo, político y académico para luchar precisamente contra la identificación, simplista y deformada, de que los jóvenes inmigrantes procedentes de zonas desfavorecidas suponían una amenaza para la seguridad pública ${ }^{27}$.

\subsection{Fracaso en Sudáfrica y caso de "Cuotas"}

El siguiente evento que ha marcado la historia de la relación entre fútbol e inmigración en Francia ocurrió hace dos años, durante el Mundial de Sudáfrica de 2010. Si bien los hechos son bien conocidos, y el objetivo del análisis no es esclarecerlos o juzgarlos, sino comprenderlos, sí que parece necesario retomar ciertos puntos claves de la historia, que permitan extraer algunas pistas explicativas de lo que se consideró como "desastre nacional". En este episodio, el periódico L'Équipe va a convertirse en un protagonista incuestionable de los hechos acontecidos.

La cronología de los hechos puede resumirse de la siguiente manera: el sábado 19 de junio, el citado periódico lanza en primicia, en una portada con todos los elementos de la prensa tabloide, los supuestos insultos 28 que el jugador Nicolas Anelka profirió al entrenador Raymond Domenech al hilo de una fuerte discusión durante el descanso del partido de fase eliminatoria que enfrentó a los Bleus contra la selección de Méjico y que acabaron perdiendo (2-0). Esa misma tarde Anelka es expulsado de la selección, y se convoca una rueda de prensa para esclarecer los hechos. El ambiente es muy tenso, sobre todo por la percepción negativa de los juga- 
dores y el equipo técnico sobre el rotativo francés, también criticado por otros medios (Beaud, 2011: 41). En dicha conferencia, será el capitán Patrick Evra quien lance un mensaje claro: la expulsión de Anelka se debió a la filtración desde el vestuario de dichos insultos, por lo que un "traidor" dentro del equipo estaría conspirando con la prensa y que "hay que eliminar del grupo", un jugador que "no quiere al equipo de Francia"29. La distancia entre prensa y equipo es más que evidente, así como en el seno del equipo. Pero aún faltaría por llegar noticia que marcaría la ruptura de la ya cuestionada imagen de los Bleus: al día siguiente, domingo 20 de junio, los jugadores deciden no entrenar, hay una fuerte discusión entre el preparador físico Robert Duverne y el capitán Evra, y los jugadores, después de unos minutos en el campo, deciden volver al autobús. Momentos después, todo en riguroso directo, Domenech lee el comunicado de los jugadores en los se rebelan ante su Federación como símbolo de protesta por la expulsión de Anelka. Jean-Pierre Escalettes, presidente de la FFF, va a responder con un comunicado calificando de "inadmisible" el comportamiento de los "jugadores que representan nuestro país" 30.

La respuesta mediática no se hace esperar: "fracaso", "desastre moral", "vergüenza" o "el hazmerreír del mundo", son algunos de los apelativos utilizados; los jugadores atraen todas las críticas y acusaciones. La situación llega a considerarse "cuestión de Estado" y de "identidad nacional", donde tanto la ministra de Salud y Deportes, Roselyne Bachelot, como el Presidente de la República Nicolas Sarkozy, van a mediar para que el equipo siga en la competición. Sin embargo, los hechos serán duramente condenados: Bachelot, en una intervención en la Asamblea Nacional, pronuncia la célebre afirmación en la que define la selección de los Bleus como "un equipo donde caïds ${ }^{31}$ inmaduros dirigen a críos asustados". Sarkozy, por su parte, recibirá en el Eliseo a Henry para aclarar los hechos, pidiendo la celebración de unos "Estados Generales del fútbol francés"32. Este intervencionismo político, por su lado, va a ser criticada tanto por la FIFA, tratándola de injerencia, como por la propia prensa ${ }^{33}$. Finalmente, llegaría la crónica de una muerte anunciada: Francia pierde 1-2 contra Sudáfrica, y es eliminada del Mundial en primera ronda quedando última de su grupo.

Los antecedentes a estos hechos evidencian una compleja problemática de circunstancias. Los Bleus fueron criticados por su falta de buen juego ya desde la fase previa de clasificación -in extremis, por el gol polémico de Henry con la mano y un Domenech constantemente puesto en duda por su falta de autoridad, también desde el discreto resultado en la Eurocopa de 2008. Antes de los graves hechos acaecidos, ya se daba por evidente la derrota de un equipo mal ensamblado, sin cohesión ${ }^{34}$.

Una de las hipótesis lanzadas por los medios, tanto prensa como televisión, sería el mal ambiente del equipo, sin un líder claro, siendo Gourkouff el jugador señalado por algunos medios como heredero del liderazgo de Zidane, y del grupo de jugadores que se habrían opuesto a la huelga. Del jugador bretón se va a enfatizar su origen y formación de "niño bien", frente a la mayoría de los jugadores proclives a la huelga, procedentes de zonas de banlieue y de orígenes más humildes; además, la supuesta existencia de "clanes" raciales y/o religiosos habría hecho difícil la convivencia dentro de la selección, hecho que se utilizó como ejemplo de lo que estaría pasando 
realmente en la sociedad. A su lado, una comparación inevitable: en el equipo de Argelia, considerada "el otro equipo de Francia", 17 de los 23 jugadores seleccionados había nacido en territorio francés ${ }^{35}$.

Las consecuencias para los Bleus fueron de una gravedad inusual: descrédito unánime del equipo, patrocinadores que deciden no seguir apoyando la selección y un notable descenso de licencias federativas (Beaud, 2010:12). Los hechos iban a marcar el final de un ciclo en el equipo, junto al escepticismo hacia un deporte considerado cada vez más grotescamente mercantilizado y falto de valores morales.

En lo que directamente concierne nuestro análisis, una de las más graves consecuencias fue la identificación de los "amotinadores" como únicos culpables de la huelga. Definidos como maleducados, egoístas o "caïds de la banda", esta imagen cristalizó el sentimiento de que el modelo educativo y de integración de los jóvenes de banlieue había fracasado: en efecto, los cinco jugadores finalmente condenados con suspensión de partidos (Anelka, Ribéry, Abidal, Evra y Gallas) eran de origen inmigrante, o procedían de zonas urbanas desfavorecidas, o convertidos al Islam como los casos de Ribéry y Abidal-. Beaud (2011) interpreta este hecho como difícilmente azaroso, aunque en ningún caso explicaría en su totalidad el origen la huelga de jugadores, y menos aún el fracaso estructural del fútbol francés; es más, en su hipótesis trata de demostrar que tanto los medios como la clase política ayudaron a crear una estigmatización de los jugadores, consiguiendo que a los ojos del mundo se redujera la causa del problema a una cuestión de origen. La selección black-blanc-beur se convierte, 12 años después de su éxito, en un problema a resolver.

Intimamente ligado al episodio que acabamos de analizar encontramos el conocido como "caso de las cuotas", acontecido pocos meses después de la huelga de jugadores, aunque finalmente vio la luz a finales de abril de 2011. Tras el fracaso del Mundial, la FFF va a colocar al frente de la dirección del equipo a Laurent Blanc, campeón del mundo en 1998. Blanc tiene un gran reto por delante: recuperar el juego y la moral de una selección mermada por la avalancha de críticas. A petición del presidente Sarkozy, el 28 de octubre de 2010 se celebra una Asamblea General en la sede de la FFF para debatir el modelo estructural del fútbol francés, elaborando nuevas estrategias de formación y detección de jóvenes jugadores, entre otros asuntos. La Federación quiere una transformación en el estilo de juego, y pone como ejemplo de la selección española, campeona de la Eurocopa 2008 y del Mundial de 2010, con un predominante juego técnico.

De nuevo, los medios vuelven a tener un papel protagonista: el periódico online Mediapart publica el 28 de abril un artículo bajo el título: "Fútbol francés: los dirigentes quieren menos negros y árabes", a raíz de una reunión celebrada el 8 de noviembre por la Dirección Técnica Nacional (DTN), encargada de la gestión de los centros de formación. En esta reunión secreta, se habría acordado establecer unas cuotas de jugadores según su raza ${ }^{36}$. Al día siguiente, la Ministra de Deportes Chantal Jouanno abre una investigación, así como la FIFA. El 30 de abril, Mediapart revela la conversación íntegra en la que se nombra la posibilidad de establecer unos límites, nunca sacados a la luz, para contar con menos jugadores negros en la selec- 
ción; según este mismo diario, las supuestas palabras de Blanc se traducen como una necesidad de "equilibrar" el grupo con jugadores más físicos (de origen africano o Dom-Tom), con otros más técnicos (árabes y blancos). La asunción de raza igual a estilo de juego es la que quedará malinterpretada y ampliamente criticada. El juicio de la prensa va a ser unánime, incluso sin haber esclarecido los hechos: la Federación Francesa es culpable de un nuevo escándalo y se le acusa de discriminación. La situación llevó a la suspensión en funciones con amonestación del director técnico nacional, aunque el seleccionador quedaría libre de cargos.

Aunque el 31 de mayo se cerró definitivamente el caso, la idea de unas posibles cuotas discriminatorias abrirá un largo debate en la opinión pública francesa. Políticos, ciudadanos, periodistas, antiguos jugadores...todos van a hacer su propio análisis de los hechos; en primer lugar, es necesario decir que ya hubo precedentes al caso de las cuotas. Los que tuvieron mayor repercusión fueron las declaraciones de Jean-Marie Le Pen en la Eurocopa de 1996, ("Francia no se reconoce del todo" en un equipo donde "hay posiblemente una proporción exagerada de jugadores de color"37; y en 2006, por parte de Georges Frêche, presidente de la Región Languedoc-Rousillon, quien subrayó el elevado número de jugadores negros en el equipo ${ }^{38}$.

Del asunto de las posibles cuotas, se confirma la presencia de la cuestión de origen en la selección de los Bleus, en este caso peyorativamente; probados o no los hechos, la polémica suscitada en la opinión pública recogida y fomentada por los medios directa o indirectamente, son muestra de un problema no resuelto con la identidad plural de su equipo nacional, y de su sociedad.

\section{Conclusiones}

Como hemos podido comprobar a través de los cuatro casos analizados, la historia migratoria del equipo de Francia ha variado enormemente, según sus éxitos o fracasos. Esta transferencia del resultado deportivo a la cohabitación de culturas es percibida como un hecho dado de manera mecánica, automática, pero es ahí precisamente donde reside la verdadera problemática: ¿hasta qué punto es una realidad o una representación? ¿De qué manera un logro deportivo puede repercutir en el día a día de una sociedad?

La selección de fútbol francesa se ha convertido en símbolo de éxito y de ascenso social para una población joven -en muchos casos bicultural-, y para la sociedad en general, como en el primer caso del Mundial del 98. Los tres últimos casos analizados han mostrado la otra cara: la de la derrota deportiva, que ha dado lugar a que interpretación del origen de los jugadores virase hacia su lado más negativo, de modo que quedaran "chivo expiatorio" de las problemas reales de la sociedad.

La construcción de un discurso en el que el fútbol es representación (a veces caricaturesca) y no una realidad ha llevado a esta situación. La creencia colectiva de un deporte integrador per se, donde gracias al ejemplo de los ídolos deportivos sería posible una eliminación de los prejuicios y las barreras culturales ha ayudado poco 
ha ayudado a mejorar esta asunción. Es cierto que el deporte posee unas cualidades socializadoras particulares, por ser un lenguaje universal y basarse en un sistema meritocrático; el deporte, además, podría aportar en cuanto a la integración un capital social: pertenecer al club, ser parte del equipo, así como establecer y consolidar redes sociales. Por esto es necesario discernir a qué tipo de deporte nos referimos: si al modelo deportivo de alta competición o de elite, convertido en fenómeno mediático y económico, o al acceso a la práctica deportiva de la población en general. Resulta interesante extraer además otras lecturas: la relación entre triunfo deportivo y la presencia política (y patriótica) en la que el futbolista o la selección se convierten en modelo a seguir en situaciones de adversidades y crisis; en este caso, frente a la dificultad de convivencia entre culturas (Barbero González, 2011).

Como también hemos visto, parte fundamental en la creación de esta corriente de opinión ha sido la prensa. Su capacidad para generar opinión y como hemos visto a lo largo del artículo, es la propia prensa (sobre todo la deportiva) quien será una protagonista más de la concatenación de los hechos ocurridos. El análisis propuesto ha buscado poner en perspectiva el papel de cronistas y comentaristas, para evitar juzgar los hechos, sino comprenderlos. Los casos analizados han sido reveladores de un cierto nombre de problemas en el aspecto deportivo, en concreto del fútbol francés, pero también de su sociedad y del problema identitario al que se enfrenta desde hace años.

En definitiva, es importante situar el fenómeno deportivo en su justo lugar, para poder comprender cómo el fútbol repercute en el proceso de integración con todos sus elementos, positivos y negativos.

\section{Bibliografía}

BARBERO GONZÁLEZ, J. I. (2011). Ficciones en torno al deporte en tiempos de crisis. Cultura, Ciencia y Deporte, $\mathrm{n}^{\circ}$ 16, p. 65-70.

BEAUD, S. (2011). Traîtes à la nation? Un autre regard sur la grêve des Bleus en Afrique du Sud. Paris: La Découverte.

BOUBEKER, A. y GALLORO, P. D. (2011). Des Italiens aux Maghrébins, d'une génération du football à l'autre. En C. BOLI, C., GASTAUT, Y y GROGNET, F. (dir.), Allez la France! Football et immigration. Paris: Gallimard-Musée National du Sport. p. 32-35.

CHECA OLMOS, F., ARJONA GARRIDO, A. y CHECA OLMOS, J. C. (2007). El extrañamiento cultural en espacios migratorios. La juventud andaluza ante el reto de la multiculturalidad. En: Migraciones internacionales, $\mathrm{n}^{\mathrm{o}}$ 4, p. 111-140.

EVENO, P. (2001). Le journal Le Monde. Une histoire d'indépendance. Paris: Odile Jacob.

GARCÍA, D. (2008). La face cachée de L'Équipe. Paris: Danger public.

GASTAUT, Y. (2008). Le sport comme révélateur des ambigüités du processus d'intégration des populations immigrées. Le cas du match de football France-Algérie. Societés Contemporaines, $\mathrm{n}^{\circ} 69$ p. 49-71.

LAGRANGE, H. (2010). Le déni des cultures. Paris: Éditions du Seuil. 
NDIAYE, P. (2010). La Condition noire. Essai sur une minorité française. Paris: Gallimard.

NOIRIEL, G. (2007). À quoi sert “l'idéntité nationale”. Marsella: Agone.

POULET, B. (2003). Le pouvoir du Monde. Quand un journal veut changer la France. Paris: La Découverte.

SIMON, P. y ZAPPI, S. (2003). La lutte contre les discriminations: la fin de l'assimilation à la française ? En: Mouvements, $\mathrm{n}^{\circ}$ 27/28, p.171-176.

QUEVAL, I. (2004). S'accomplir ou se dépasser: essai sur le sport contemporain. Paris: Gallimard.

\section{Páginas web}

MEUNIER y CANAL + (2008). Les yeux dans les Bleux. Disponible en http://www.daily motion.com/video/x8j5r4_mondial-98-les-yeux-dans-les-bleus_sport. Consultada el 20-05-2012.

\section{Notas}

1 Literalmente: "negro, blanco y árabe”. El juego de palabras hace alusión a la bandera francesa tricolor, siendo esta nueva apelación la que se mostrara como símbolo de diversidad dentro y fuera del equipo. La palabra beur, viene del argot francés verlan (à l'envers o al revés), donde se invierten o modifican las sílabas de las palabras; este lenguaje comenzó a ser usado en por las clases obreras y población inmigrante de zonas urbanas desfavorecidas, partir de los años 90, aunque en la actualidad está ampliamente difundido gracias al cine o la música (rap).

2 En castellano: "azules". De esta forma se hace referencia a las selecciones deportivas que representan a Francia.

3 En teoría migratoria, el asimilacionismo se caracteriza por entender la integración como un proceso natural por el cual los diferentes grupos étnicos terminan compartiendo una cultura común y adquieren una similar estructura de oportunidad en la sociedad; dicho de otro modo, los inmigrantes abandonan paulatinamente los modelos culturales y conductuales de origen en favor de los patrones de la sociedad de llegada.

4 En francés: Departaments et Territoires d'Outre Mer.

5 Banlieue significa literalmente "suburbio" o "extrarradio". En el caso de las grandes aglomeraciones urbanas en Francia, como en París, Lyon o Marsella, se utiliza este término para referirse a ciertas zonas urbanas periféricas, en su mayoría de viviendas sociales, y con población con recursos económicos medios o bajos, una alta tasa de paro, y un notable porcentaje de población inmigrante. Es precisamente una doble identificación cultural y social la que se da en este contexto urbano específico.

6 Observatoire de la Presse, 22-03-2012. Consultado el 25-05-2012. En: http://observatoire.ojd.com/report/visu/obs/22/do/GP_PQN/ 
7 Le Monde, 18-7-1998.

8 L'Équipe, 9-07-1998.

9 Le Monde,24-06-1998.

10 Le Monde, 12-06-1998

11 L'Équipe, 13-07-1998.

12 Le Monde, 12-06-1998.

13 Le Monde, 18-07-1998.

14 Le Monde, 14-07-1998.

15 Le Monde, 13-07-1998.

16 L'Équipe, 15-07-1998.

17 L'Équipe, 11-08-1998.

18 Le Monde, 22-12-1998.

19 L'Équipe, 04-10-2001.

20 L'Équipe, 06-10-2001.

21 L'Équipe, 09-10-2001.

22 L'Équipe, 05-10-2001.

23 Le Monde, 09-10-2001.

24 Thuram, nacido en Guadalupe, quedó personalmente marcado por estos hechos; más tarde formaría parte del Alto Consejo de la Integración; es conocido su compromiso social sobre la cuestión de la educación contra el racismo a través de la Fundación que lleva su nombre, y en la cual participan importantes referencias académicas, como el sociólogo Michel Wieviorka o el historiador Pascal Blanchard. Según Thuram, la manera de combatir el racismo comienza con una reflexión y una educación sobre la historia, para comprender cómo la distinción racial se construyó con el objeto de conseguir la dominación y la esclavitud. En: http://www.thuram.org/site/, consultada el 23-05-2012.

25 L'Équipe, 07-10-2001.

26 L'Équipe, 09-10-2001.

27 Le Monde, 22-12-2001.

28 La portada de L'Équipe, en efecto, mostraba con un fotomontaje a Anelka y Domenech enfrentados cara a cara, y con el titular en grades rótulos: "va te faire enculer, sale fils de pute!” (literalmente, “iqué te den, sucio hijo de puta!”).

29 L'Équipe.fr,19-05-2010, en: http://www2.lequipe.fr/Football/breves 2010/20100619 203722 _eliminer-le-traitre.htmlconsultada el 13-05-2012.

30 FFF.fr, 20-05-2010, en: http://www.fff.fr/bleus/actu/533838.shtml, consultada el 13-05-2012. 
31 "Caïd" es un término con diversas acepciones: por un lado, puede hace referencia a una autoridad musulmana, al oficial de máximo rango de un regimiento, o de manera coloquial, al líder o cabecilla de una banda delictiva o criminal.

32 Le Monde.fr, 23-06-2010. En: http://www.lemonde.fr/sport/article/2010/06/23 /nicolas-sarkozy-va-recevoir-thierry-henry_1377602_3242.html, consultada el 1505-2012.

33 Le Monde, 05-07-2010.

34 L'Équipe, 07-06-2010.

35 Le Monde, 17-07-2010.

36 Mediapart.fr, 28-04-2011. En: http://www.mediapart.fr/journal/international/ 280411/foot-francais-les-dirigeants-veulent-moins-de-noirs-et-darabes., consultada el 12-05-2012.

37 Le Monde, 11-06-2011.

38 Le Monde, 06-07-2006.

39 Le Monde, 23-11-2006.

\section{La autora}

Noemi García-Arjona es Personal Investigador en Formación de la Universidad Politécnica de Madrid y miembro del grupo de investigación ESHAFYD (Estudios Sociales y Humanistas en la Actividad Física y el Deporte). Su investigación está orientada al análisis de las políticas deportivas urbanas de Francia y España, así como al papel histórico, social y político que desempeña el deporte en la integración de jóvenes inmigrantes y de segunda generación. 